\title{
Development of an Intermittent-Flow Enantioselective aza-Henry Reaction using an Arylnitromethane and Homogeneous Brønsted Acid-Base Catalyst with Recycle
}

\author{
Sergey V. Tsukanov, Martin D. Johnson, Scott A. May, Morgan Rosemeyer, Michael A. Watkins, Stanley P. \\ Kolis, Matthew H. Yates and Jeffrey N. Johnston
}

Small Molecule Design and Development, Eli Lilly and Company, Indianapolis, Indiana 46285, Unites States

And

Department of Chemistry and Vanderbilt Institute of Chemical Biology, Vanderbilt University, Nashville, Tennessee 37235, United States

1. Calculation of conversion versus time in batch PFR, CSTR and CSTRs in series .................................2

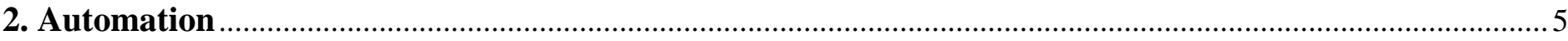

3. HPLC data

Figure S1. HPLC traces for the solid product $(10$ cycles, $80 \%$ recycling ratio) ...................................................... 7

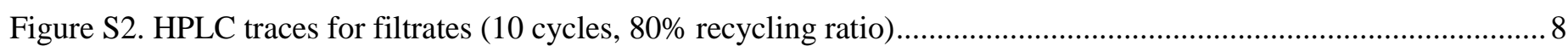

Figure S3. HPLC trace for the isolated dried product (10 cycles, $80 \%$ recycling ratio) ............................................

Figure S4. Chiral HPLC trace for the isolated dried product (10 cycles, 80\% recycling ratio) .................................. 10

Figure S5. HPLC traces for the solid product (24 cycles, 97\% recycling ratio) ....................................................... 11

Figure S6. HPLC traces for filtrates (24 cycles, 97\% recycling ratio) ................................................................... 13

Figure S7. Chiral HPLC trace for the isolated dried product (cycles 1-6, 24 cycles, 97\% recycling ratio) ................... 15

Figure S8. Chiral HPLC trace for the isolated dried product (cycles 7-16, 24 cycles, 97\% recycling ratio) ................. 16

Figure S9. HPLC traces for the solid product (24 cycles, 97\% recycling ratio) ...................................................... 17

4. Preliminary safety evaluation of oxime and nitro containing compounds …........................................ 18

Figure S10. DSC analysis for 1-chloro-4-(nitromethyl)benzene …...................................................................... 19

Figure S11. DSC analysis for tert-butyl-(1R,2S)-1,2-bis(4-chlorophenyl)-2-(nitroethyl)carbamate .............................20

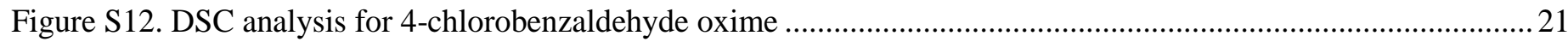

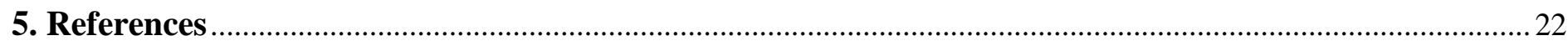




\section{Calculation of conversion versus time in batch PFR, CSTR and CSTRs in series}

This section illustrates how to derive the design equations for different reactor types and use them to calculate conversion versus time in batch, PFR, CSTR, and CSTRs in series.

To illustrate why a CSTR requires longer residence time than PFR or batch for full conversion, consider a first order irreversible reaction that requires 30 minutes for $99.9 \%$ conversion batch. In an ideal PFR, the required reaction time is also 30 minutes for $99.9 \%$ conversion, but in an ideal CSTR, the required reaction time is 72 hours for $99.9 \%$ conversion, which is impractical. The required total residence time in 3 equal-volume CSTRs in series would be 1.95 hours, which is significantly less than a single CSTR. However, this is still a significantly longer reaction time than batch or PFR, and it does not enable the type of controlled addition of imine to nitroalkane that is desired.

\section{Case 1. Batch reactor}

$$
[\text { in }- \text { out }]+\text { reaction }=\text { accumulation }
$$

batch reaction no flow in and out

$$
\begin{gathered}
\text { reaction }=\text { accumulation } \\
-k C_{A}=\frac{d C_{A}}{d t}
\end{gathered}
$$

$C_{A}=$ concentration of reagent $\mathrm{A}$ at one point in reactor

$k=$ first order rate constant

$t=$ reaction time

Integrate over time:

$$
\int_{0}^{t}-k d t=\int_{C_{A o}}^{C_{A F}} \frac{d C_{A}}{C_{A}}
$$

$C_{A 0}=$ Initial concentration of reagent $\mathrm{A}$

$C_{A F}=$ Final concentration of reagent $\mathrm{A}$

$$
\begin{gathered}
-k t=\ln \left(\frac{C_{A F}}{C_{A o}}\right) \\
\frac{C_{A F}}{C_{A o}}=e^{-k t} \\
t=30 \mathrm{~min} \\
\frac{C_{A F}}{C_{A o}}=0.001
\end{gathered}
$$

Calculate first order rate constant

$$
k=0.2303 \frac{1}{\min }
$$

Case 2. PFR.

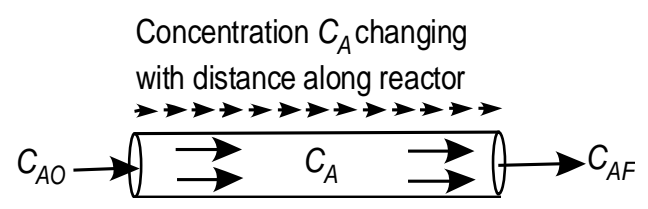


$C_{\mathrm{A} 0}=$ Initial concentration of reagent $\mathrm{A}$ at reactor inlet

$C_{A F}=$ Final concentration of reagent A reactor outlet

$C_{A}=$ Concentration of reagent $\mathrm{A}$ at one point in PFR

$$
\tau=\frac{L}{v_{x}} \text { seconds }
$$

$L=$ total reactor length

$v_{x}=$ average linear velocity in reactor

$$
[\text { in }- \text { out }]+\text { reaction }=\text { accumulation }
$$

Steady state no accumulation

$$
\begin{aligned}
& {[\text { in }- \text { out }]+\text { reaction }=0} \\
& \frac{D}{u L} \frac{d^{2} C_{A}}{d x^{2}}-v_{x} \frac{d C_{A}}{d x}-k C_{A}=0
\end{aligned}
$$

Assume negligible axial dispersion.

$$
-v_{x} \frac{d C_{A}}{d x}-k C_{A}=0
$$

Integrate over distance:

$$
\begin{gathered}
\int_{C_{A o}}^{C_{A F}} \frac{d C_{A}}{C_{A}}=\int_{0}^{L} \frac{-k}{v_{x}} d x \\
\ln \left(\frac{C_{A F}}{C_{A o}}\right)=-\frac{k L}{v_{x}}=-k \tau \\
\frac{C_{A F}}{C_{A o}}=e^{-k \tau}
\end{gathered}
$$

Given rate constant and time:

$$
\begin{gathered}
k=0.2303 \frac{1}{\min } \\
t=30 \mathrm{~min}
\end{gathered}
$$

Calculate conversion:

$$
\frac{C_{A F}}{C_{A o}}=0.001
$$

For the same rate constant and the same time, conversion is the same in the ideal PFR and the batch reactor.

\section{Case 3. CSTR.}

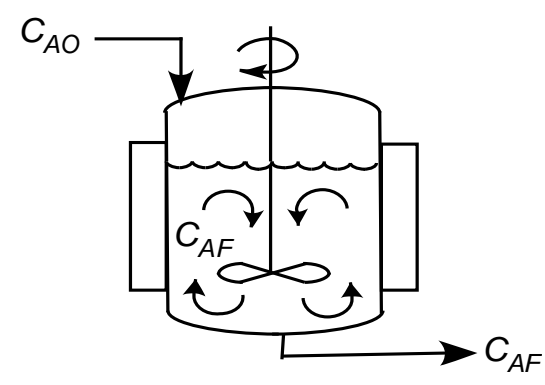




$$
\tau=\frac{V}{Q} \text { seconds }
$$

$V=$ volume of fluid in CSTR

$Q=$ volumetric flow rate in CSTR

$$
[\text { in }- \text { out }]+\text { reaction }=\text { accumulation }
$$

Steady state no accumulation

$$
\begin{gathered}
{[\text { in }- \text { out }]+\text { reaction }=0} \\
Q C_{A o}-Q C_{A F}-k C_{A F} V=0 \\
Q C_{A o}=C_{A F}(Q+k V)=0 \\
\frac{C_{A F}}{C_{A o}}=\frac{Q}{Q+k V} \\
\frac{C_{A F}}{C_{A o}}=\frac{1}{1+k \tau}
\end{gathered}
$$

Given rate constant and conversion:

$$
\begin{gathered}
k=0.2303 \frac{1}{\min } \\
\frac{C_{A F}}{C_{A o}}=0.001
\end{gathered}
$$

Calculate mean reactor residence time:

$$
\tau=4326 \text { minutes }=72.1 \text { hours }
$$

\section{Case 4. CSTRs-in-series.}

See chemical engineering texts for CSTRs in series. ${ }^{1}$

$$
\frac{C_{A F}}{C_{A o}}=\left(\frac{1}{1+k \tau}\right)^{3}
$$

Given reaction rate and conversion:

$$
\begin{gathered}
k=0.2303 \frac{1}{\min } \\
\frac{C_{A F}}{C_{A o}}=0.001
\end{gathered}
$$

Calculate mean reactor residence time:

$$
\begin{gathered}
\tau=39.1 \text { minutes in each equal sized CSTR } \\
\text { therefore overall } \tau=117 \text { minutes. }
\end{gathered}
$$




\section{Automation}

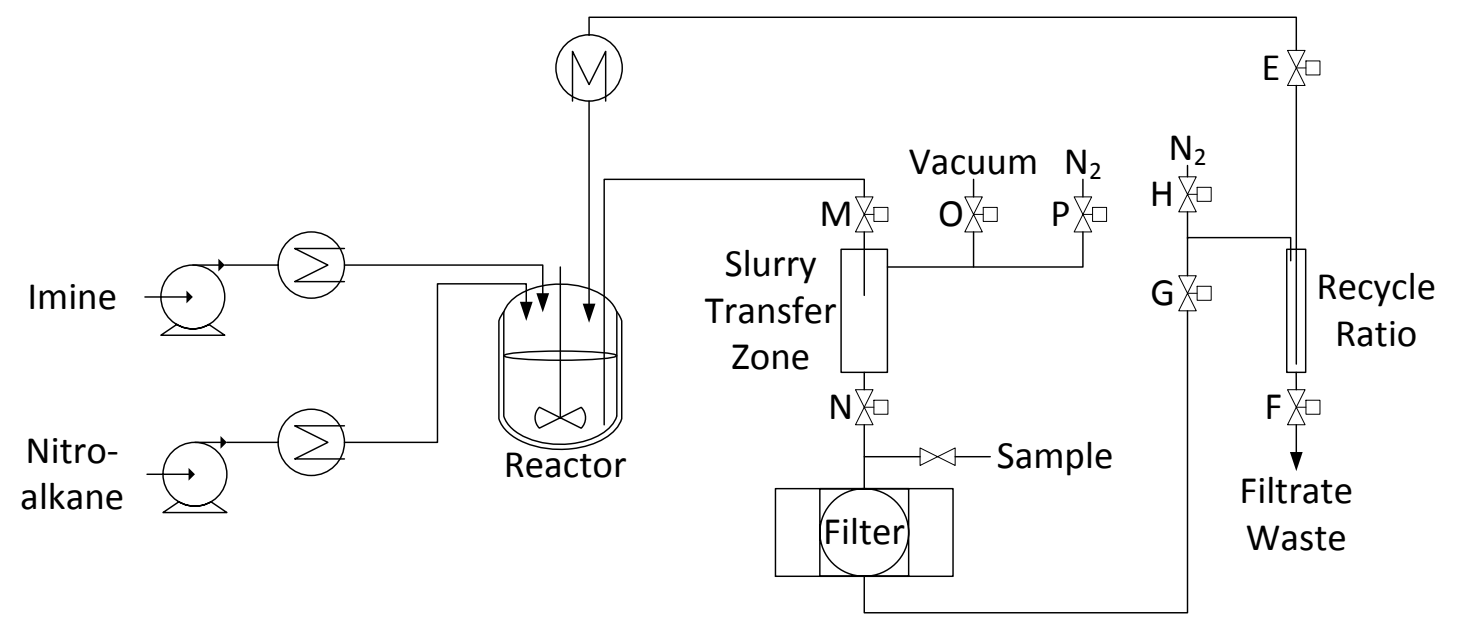

Scheme S1. Technological scheme of the process

DeltaV was used for automation of the laboratory intermittent flow CSTR system. Refer to the figure with reactor system schematic and labeled valve numbers (Scheme 1). The automation starts with the two pumps charging material into the reactor. Once the last pump turns off the reaction extra stir time begins. Total reaction time is the reagent addition time plus the extra stir time. When the reaction is finished, valves $\mathrm{G}$ and $\mathrm{E}$ are open to allow for filtrate to flow back to the reactor. Valve $\mathrm{O}$ opens to pull vacuum on the slurry transfer zone. A vacuum regulator is used to make sure that the MNOP transfer zone pulls down to the desired pressure, for example $400 \mathrm{mmHg}$. Valve $\mathrm{O}$ closes and valve $\mathrm{M}$ opens to allow the contents of the reactor to be pulled into the transfer zone. Valve $\mathrm{M}$ closes and the transfer zone is pressured up with nitrogen by opening valve $\mathrm{P}$. Valve $\mathrm{N}$ opens to start the flow of material to the filter. Nitrogen pressure continues to push on the top of the filter, so that the filtrate flows through the filter and back to the reactor. Valve P closes, but the pressure on the top of the filter continues to push filtrate back to reactor for the filter time input by the user. When the solids have collected on the filter and the filtrate has been recycled, valves $\mathrm{N}, \mathrm{G}$ and $\mathrm{E}$ close. The EFGH zone contains filtrate waste. The volume of filtrate waste depends on how far the dip tube is pushed down into EFGH zone. The next step is for this filtrate waste to be pushed to a waste container. Valve H opens to pressurize EFGH zone, then Valve $\mathrm{H}$ closes. Valve F opens to transfer the filtrate waste to the waste container. Valve F closes and the cycle wait time starts. When the cycle wait time is complete, the sequence will repeat until the user turns the sequence off.

For DeltaV automation of this cart the following variables can be adjusted by the user: time between each cycle, when pumps $1 \& 2$ turn on and off, the reaction time, vacuum time in transfer zone, amount of time to transfer from the reactor to the transfer zone, time to pressure up the transfer zone with nitrogen, time for slurry to pass through filter, time to pressure up transfer zone for filtrate waste, and the time to push filtrate waste out of the second transfer zone.

The automation sequence for DeltaV may be seen below:

Pump 2 on, wait 1 minute

Pump 2 off

Pump 1 on, wait 23.5 minutes

Pump 1 off, wait 5.5 minutes (reaction extra stir time)

Open G,

Open E,

Open O, $30 \mathrm{sec}$

Close $\mathrm{O}$

Open M, $60 \mathrm{sec}$

Close M

Open P, 3 sec

Open N

Close $\mathrm{P}$, wait $5 \mathrm{~min}$

Close $\mathrm{N}$ 
Close G

Close E

Open H, 5 sec

Close H

Open F, $5 \mathrm{sec}$

Close F, wait $5 \mathrm{sec}$

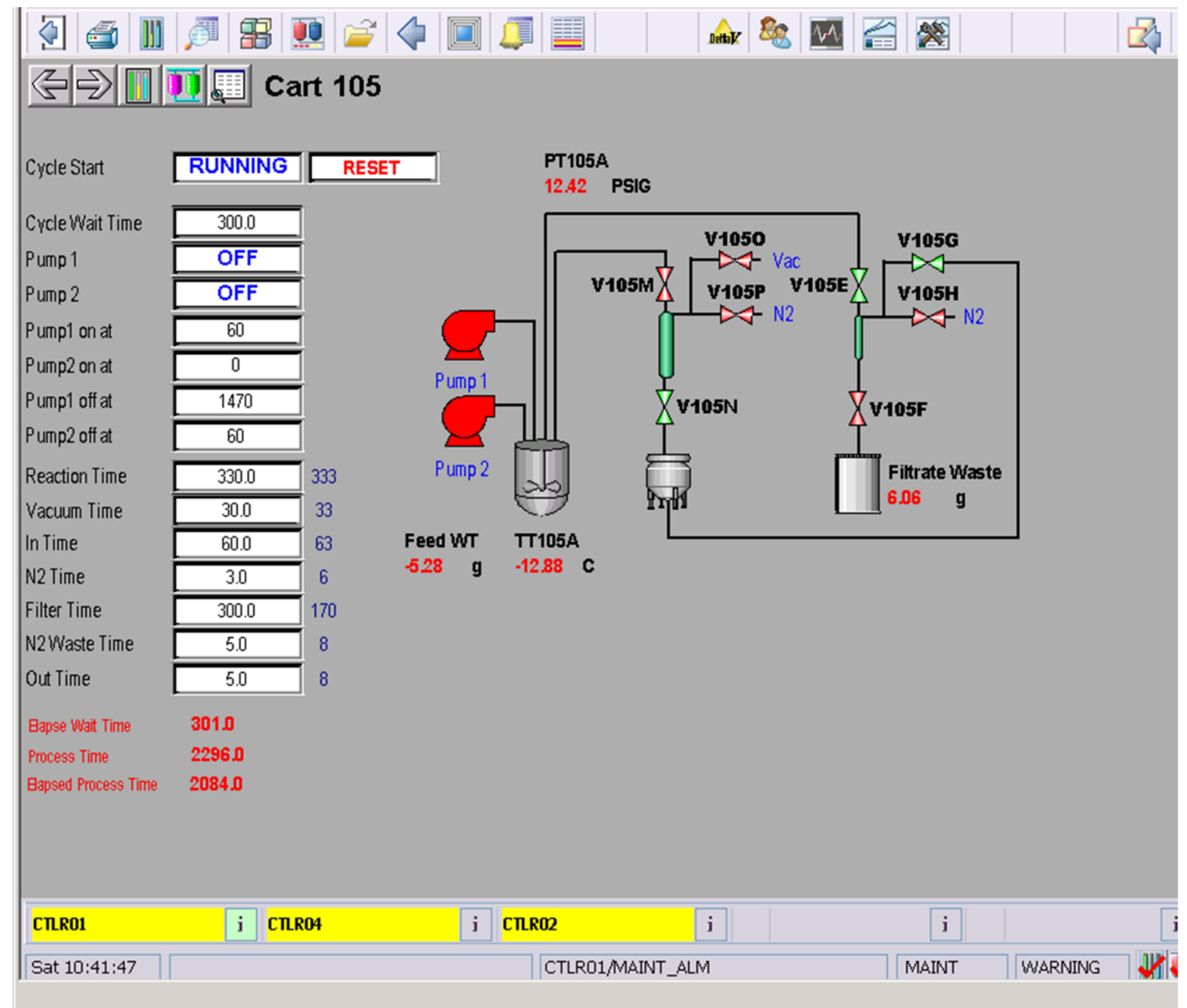

Picture S1. Screen shot of the control screen of the process 


\section{HPLC data}

Figure S1. HPLC traces for the solid product (10 cycles, $80 \%$ recycling ratio)

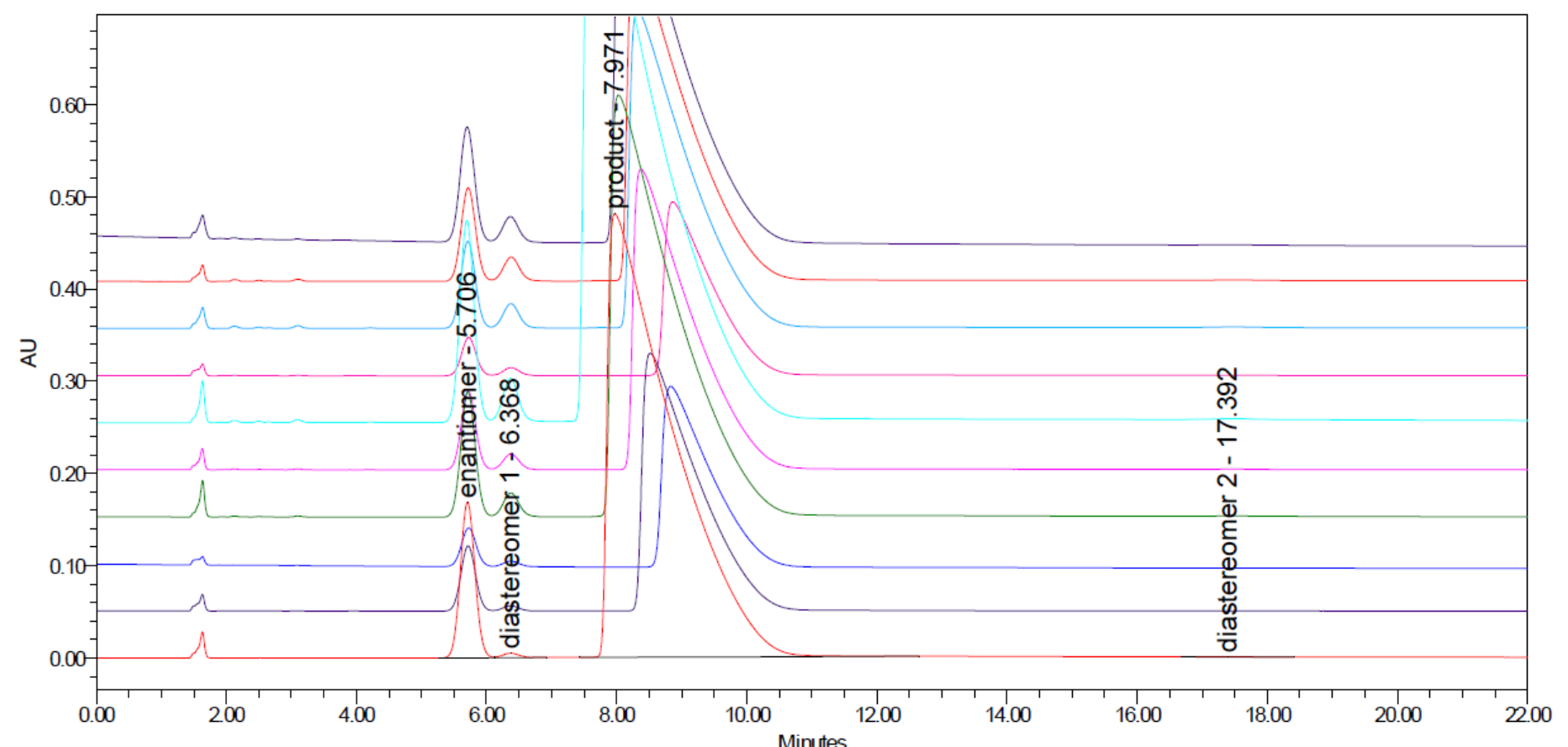

SampleName 73-11

SampleName 73-21

SampleName 73-31

SampleName 73-41

SampleName 73-51

SampleName 73-61

SampleName 73-71

SampleName 73-81

SampleName 73-91

SampleName 73-101

Component

Sum mary For

Percent_ee

\begin{tabular}{|r|l|r|}
\hline & $\begin{array}{c}\text { Sample } \\
\text { Name }\end{array}$ & product \\
\hline 1 & $73-11$ & 85.1 \\
\hline 2 & $73-21$ & 86.9 \\
\hline 3 & $73-31$ & 87.5 \\
\hline 4 & $73-41$ & 87.0 \\
\hline 5 & $73-51$ & 87.2 \\
\hline 6 & $73-61$ & 87.1 \\
\hline 7 & $73-71$ & 87.0 \\
\hline 8 & $73-81$ & 86.8 \\
\hline 9 & $73-91$ & 86.6 \\
\hline 10 & $73-101$ & 86.8 \\
\hline
\end{tabular}

Component Sum mary For \% Area

\begin{tabular}{|r|l|r|r|r|r|r|}
\hline & $\begin{array}{c}\text { Sample } \\
\text { Name }\end{array}$ & enantiomer & diastereomer 1 & nitrcalkane & product & diastereomer 2 \\
\hline 1 & $73-11$ & 7.44 & 0.24 & & 92.31 & 0.02 \\
\hline 2 & $73-21$ & 6.50 & 0.59 & & 92.89 & 0.02 \\
\hline 3 & $73-31$ & 6.18 & 0.98 & & 92.80 & 0.03 \\
\hline 4 & $73-41$ & 6.40 & 1.35 & & 92.18 & 0.07 \\
\hline 5 & $73-51$ & 6.32 & 1.41 & & 92.19 & 0.08 \\
\hline 6 & $73-61$ & 6.33 & 1.53 & & 92.04 & 0.09 \\
\hline 7 & $73-71$ & 6.38 & 1.49 & & 92.03 & 0.10 \\
\hline 8 & $73-81$ & 6.47 & 2.03 & 0.02 & 91.28 & 0.20 \\
\hline 9 & $73-91$ & 6.59 & 1.87 & 0.01 & 91.51 & \\
\hline 10 & $73-101$ & 6.51 & 1.59 & & 91.82 & 0.07 \\
\hline
\end{tabular}


Figure S2. HPLC traces for filtrates (10 cycles, $80 \%$ recycling ratio)

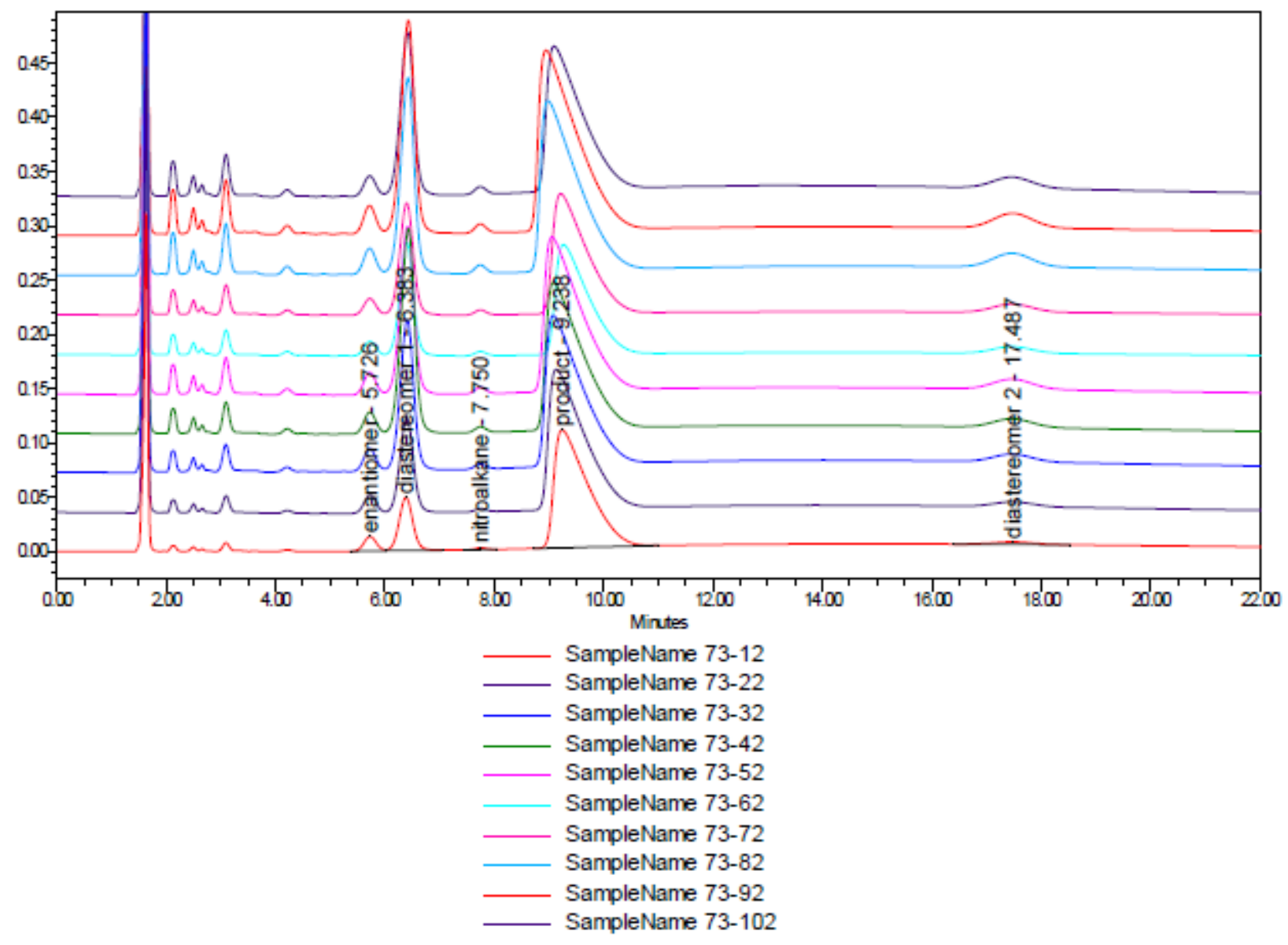

Component

Sum mary For

Percent_ee

\begin{tabular}{|r|l|r|}
\hline & $\begin{array}{c}\text { Sanple } \\
\text { Name }\end{array}$ & product \\
\hline 1 & $73-12$ & 91.3 \\
\hline 2 & $73-22$ & 91.3 \\
\hline 3 & $73-32$ & 90.2 \\
\hline 4 & $73-42$ & 90.3 \\
\hline 5 & $73-52$ & 90.5 \\
\hline 6 & $73-62$ & 90.8 \\
\hline 7 & $73-72$ & 90.2 \\
\hline 8 & $73-82$ & 90.3 \\
\hline 8 & $73-82$ & 90.2 \\
\hline 10 & $73-102$ & 90.8 \\
\hline
\end{tabular}

Component Sum mary For \% Area

\begin{tabular}{|c|c|c|c|c|c|c|}
\hline & $\begin{array}{l}\text { Sample } \\
\text { Name }\end{array}$ & enartioner & diastereomer 1 & nitroakne & product & dastereoner 2 \\
\hline 1 & $73-12$ & 3.50 & 14.65 & 0.41 & 7929 & 208 \\
\hline 2 & $73-22$ & 3.35 & 18.56 & 0.55 & 73.65 & 280 \\
\hline 3 & $73-32$ & 3.42 & 25.56 & 0.70 & 68.42 & 3.80 \\
\hline 4 & $73-42$ & 3.05 & 3232 & 0.73 & 59.86 & 3.80 \\
\hline 5 & $73-52$ & 3.20 & 26.91 & 0.85 & 6423 & 4.65 \\
\hline 6 & $73-62$ & 3.14 & 27.61 & 0.86 & 63.48 & 4.77 \\
\hline 7 & $73-72$ & 3.35 & 25.10 & 0.83 & 6501 & 5.41 \\
\hline 8 & $73-82$ & 3.21 & 27.21 & 0.96 & 6288 & 5.50 \\
\hline 9 & $73-82$ & 3.24 & 27.35 & 0.85 & 6283 & 5.41 \\
\hline 10 & $73-102$ & 3.04 & 27.68 & 1.05 & 6270 & 5.32 \\
\hline
\end{tabular}


Figure S3. HPLC trace for the isolated dried product (10 cycles, $80 \%$ recycling ratio)

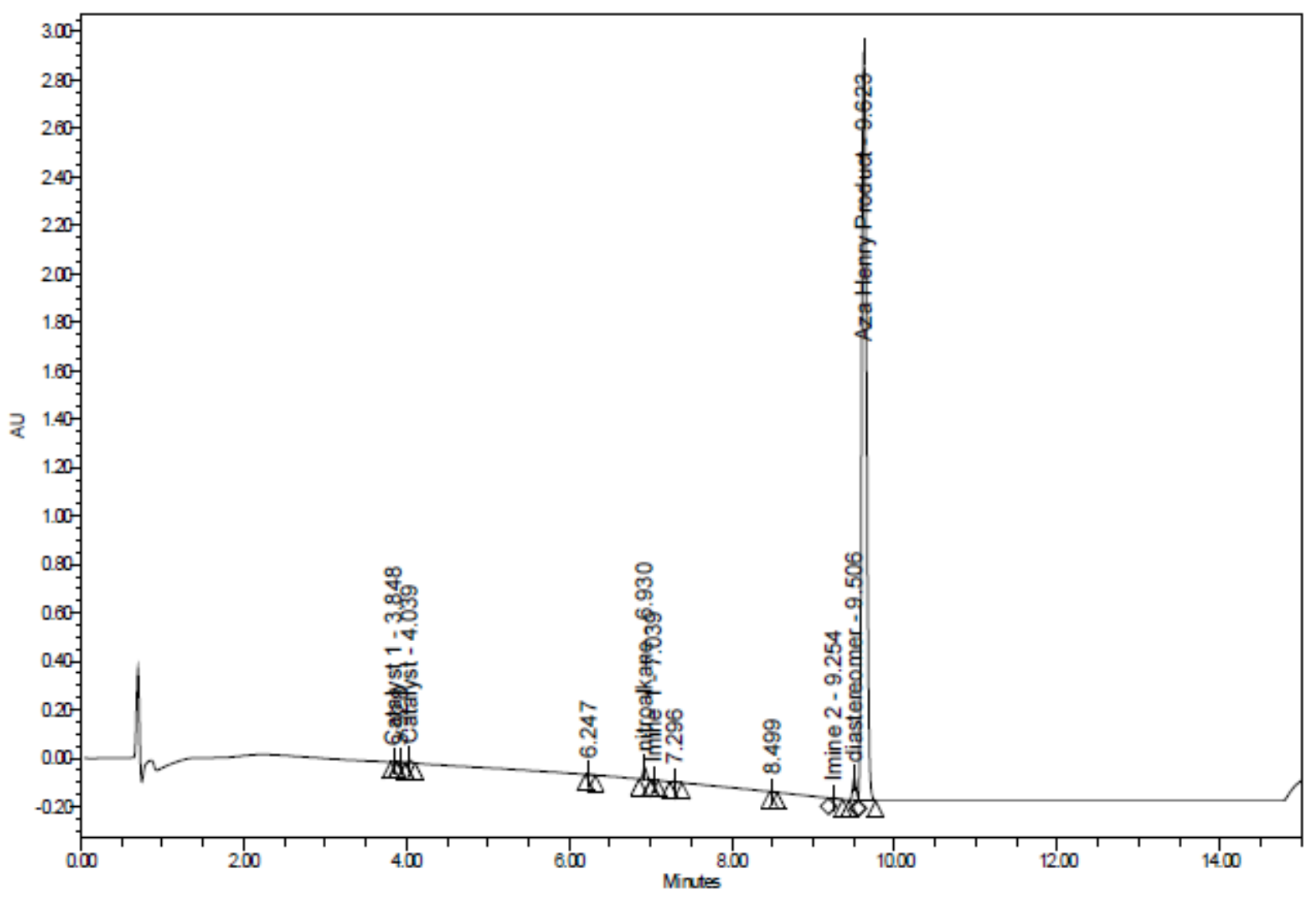

\begin{tabular}{|c|c|c|c|c|}
\hline & Name & $\begin{array}{c}\text { RT } \\
(\mathrm{min})\end{array}$ & $\begin{array}{c}\text { Ares } \\
\left(\mu V^{*} \sec \right)\end{array}$ & $\%$ Area \\
\hline 1 & Catalyst 1 & 3.848 & 2615 & 0.02 \\
\hline 2 & & 3.828 & 4346 & 0.03 \\
\hline 3 & Catalyst & 4.039 & 33823 & 0.26 \\
\hline 4 & & 6.247 & 4787 & 0.04 \\
\hline 5 & nitroalkne & 6.830 & 148179 & 1.14 \\
\hline 6 & Imine 1 & 7.030 & 5534 & 0.04 \\
\hline 7 & & 7296 & 12740 & 0.10 \\
\hline 8 & & 8.490 & 2480 & 0.02 \\
\hline 9 & Imine 2 & 8.254 & 14247 & 0.11 \\
\hline 10 & diastereamer & 9.506 & 269298 & 208 \\
\hline 11 & Aza Herry Product & 9.623 & 12565416 & 96.18 \\
\hline
\end{tabular}


Figure S4. Chiral HPLC trace for the isolated dried product (10 cycles, $80 \%$ recycling ratio)

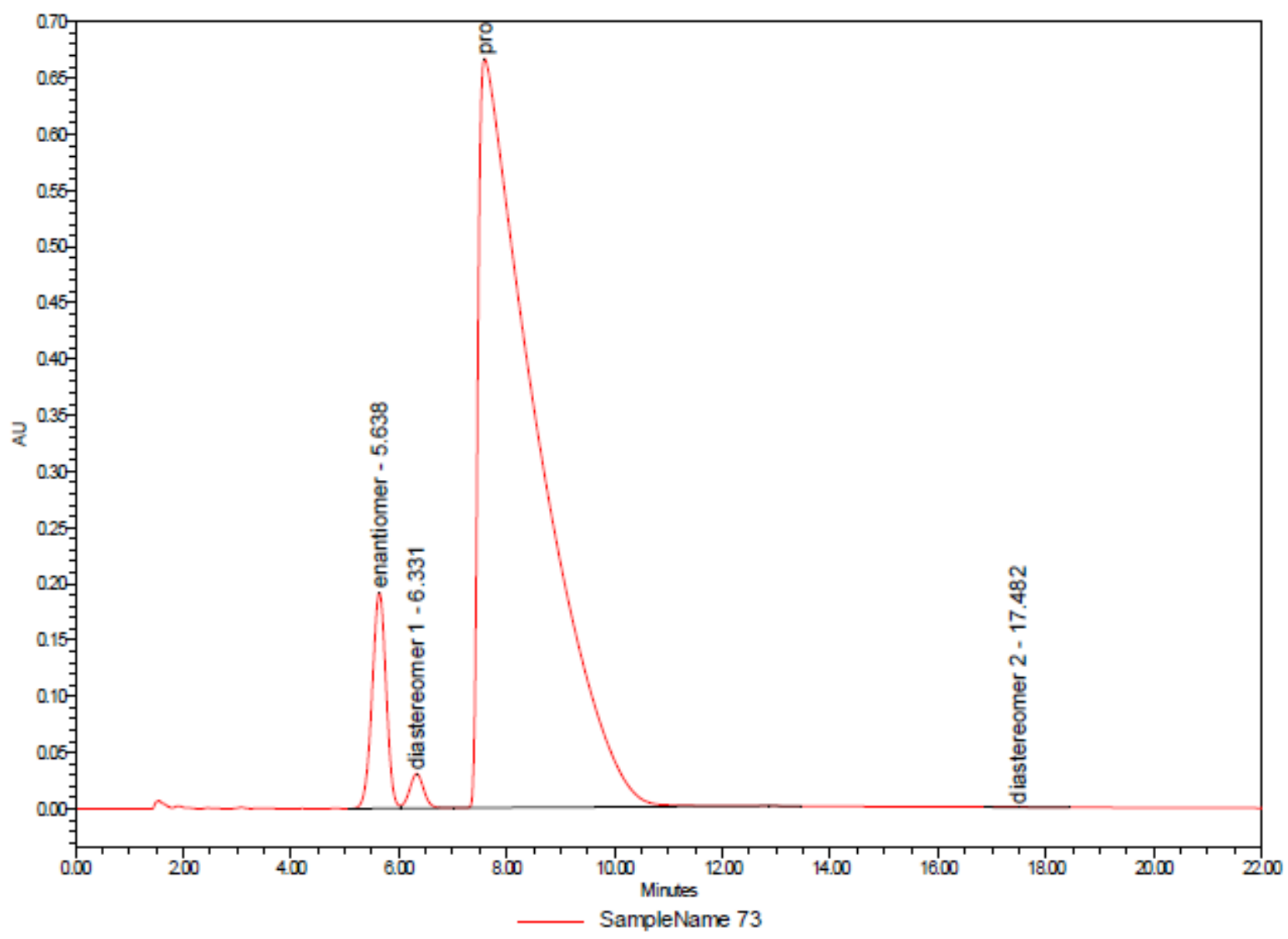

Component
Summary For
Percent_ee
\begin{tabular}{|l|l|r|}
\hline & $\begin{array}{c}\text { Sample } \\
\text { Name }\end{array}$ & product \\
\hline 1 & 73 & 87.0 \\
\hline
\end{tabular}

Component Summ ary For \% Area

\begin{tabular}{|l|l|r|r|r|r|}
\hline & $\begin{array}{c}\text { Sanple } \\
\text { Name }\end{array}$ & enartioner & dastereoner 1 & product & diatereoner 2 \\
\hline 1 & 73 & 6.41 & 1.03 & 9254 & 0.01 \\
\hline
\end{tabular}


Figure S5. HPLC traces for the solid product (24 cycles, 97\% recycling ratio)

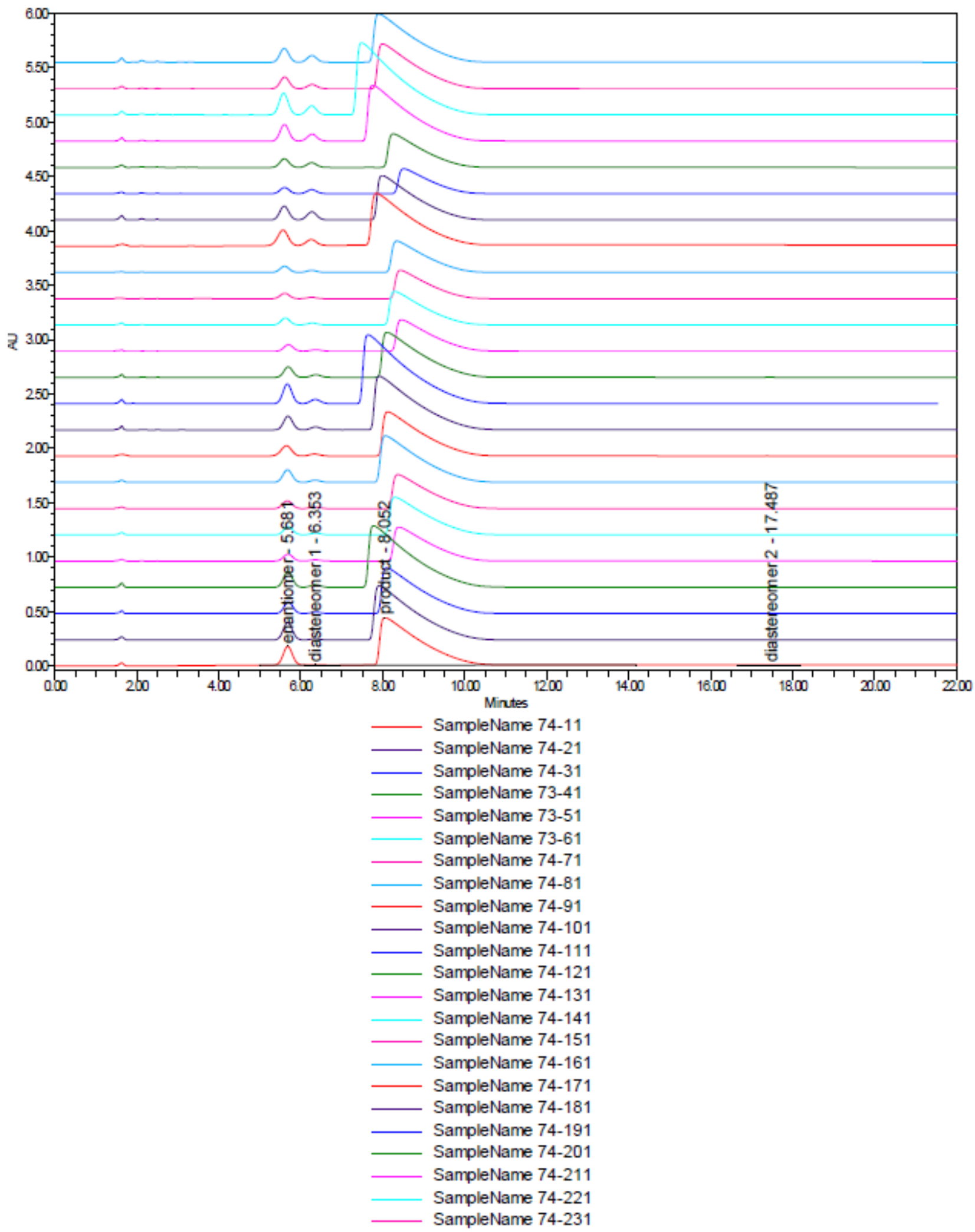


Component Summary For \% Area

\begin{tabular}{|c|c|c|c|c|c|c|c|c|}
\hline \multicolumn{9}{|c|}{ Component summary ror \% Area } \\
\hline \multirow{13}{*}{\multicolumn{3}{|c|}{$\begin{array}{l}\text { Component } \\
\text { Summary For } \\
\text { Percent_ee }\end{array}$}} & & $\begin{array}{l}\text { Sample } \\
\text { Name }\end{array}$ & enartioner & diastereomer 1 & product & dizstereomer 2 \\
\hline & & & 1 & 7411 & 8.60 & 0.29 & 91.00 & 0.02 \\
\hline & & & 2 & 7421 & 6.86 & 0.47 & 9258 & 0.0 \\
\hline & & & 3 & 7431 & 5.79 & 0.80 & 83.38 & 0.02 \\
\hline & & & 4 & $73-41$ & 5.22 & $0 \oplus$ & 9284 & 0.29 \\
\hline & & & 5 & $73-51$ & 5.28 & 1.06 & 83.62 & 0.04 \\
\hline & & & 6 & $73-61$ & 5.33 & 1.18 & 83.41 & 0.06 \\
\hline & & & 7 & 7471 & 5.91 & 1.32 & 9273 & 0.04 \\
\hline & & & 8 & 7481 & 6.20 & 1.18 & 8260 & 0.02 \\
\hline & & & 8 & 7491 & 6.15 & 1.24 & 9258 & 0.03 \\
\hline & & & 10 & $74-101$ & 5.48 & 1.27 & 83.19 & 0.06 \\
\hline & & & \begin{tabular}{|l|}
11 \\
\end{tabular} & $74-111$ & 5.71 & 1.35 & 9289 & 0.06 \\
\hline & & & 12 & 74121 & 5.31 & 1.51 & 83.12 & 0.06 \\
\hline \multirow{2}{*}{\multicolumn{2}{|c|}{$\begin{array}{l}\text { Sample } \\
\text { Name }\end{array}$}} & \multirow{2}{*}{ product } & 13 & 74131 & 5.30 & 1.36 & 83.17 & 0.04 \\
\hline & & & 14 & 74141 & 5.27 & 1.63 & 9298 & 0.00 \\
\hline 1 & 7411 & 826 & 15 & $74-151$ & 5.34 & 1.50 & 8300 & 0.06 \\
\hline 2 & 7421 & 880 & 16 & 74161 & 5.28 & 1.87 & 8269 & 0.14 \\
\hline 3 & $74-31$ & 883 & \begin{tabular}{|l|}
17 \\
\end{tabular} & 74171 & 7.24 & 272 & 9003 & 0.01 \\
\hline 4 & $73-41$ & 894 & 18 & $74-181$ & 6.98 & 443 & 88.45 & 0.14 \\
\hline 5 & $73-51$ & 894 & 19 & $74-191$ & 6.80 & 4.81 & 88.13 & 0.21 \\
\hline 6 & $73-61$ & 892 & 20 & 74201 & 6.54 & 3.81 & 89.46 & 0.17 \\
\hline 7 & 7471 & 880 & 21 & 74211 & 6.32 & 287 & 90.72 & 0.00 \\
\hline 8 & 7481 & 87.4 & 22 & 74221 & 6.00 & 271 & 9100 & 0.10 \\
\hline 8 & 7491 & 87.5 & 23 & 74231 & 6.00 & 237 & 91.47 & 0.07 \\
\hline 10 & \begin{tabular}{|l|}
$74-101$ \\
\end{tabular} & 889 & 24 & 74241 & 6.46 & 3.42 & 89.86 & 0.23 \\
\hline 11 & $74-111$ & 884 & & & & & & \\
\hline 12 & $74-121$ & 892 & & & & & & \\
\hline 13 & $74-131$ & 89.1 & & & & & & \\
\hline 14 & 74141 & 893 & & & & & & \\
\hline 15 & $74-151$ & 892 & & & & & & \\
\hline 16 & $74-161$ & 892 & & & & & & \\
\hline 17 & $74-171$ & 85.1 & & & & & & \\
\hline 18 & $74-181$ & 85.4 & & & & & & \\
\hline 18 & $74-191$ & 85.7 & & & & & & \\
\hline 20 & 74201 & 884 & & & & & & \\
\hline 21 & 74211 & 870 & & & & & & \\
\hline 22 & 74221 & 87.5 & & & & & & \\
\hline 23 & 74231 & 87.5 & & & & & & \\
\hline 24 & 74241 & 88.6 & & & & & & \\
\hline
\end{tabular}

Component

Sum mary For Percent_ee

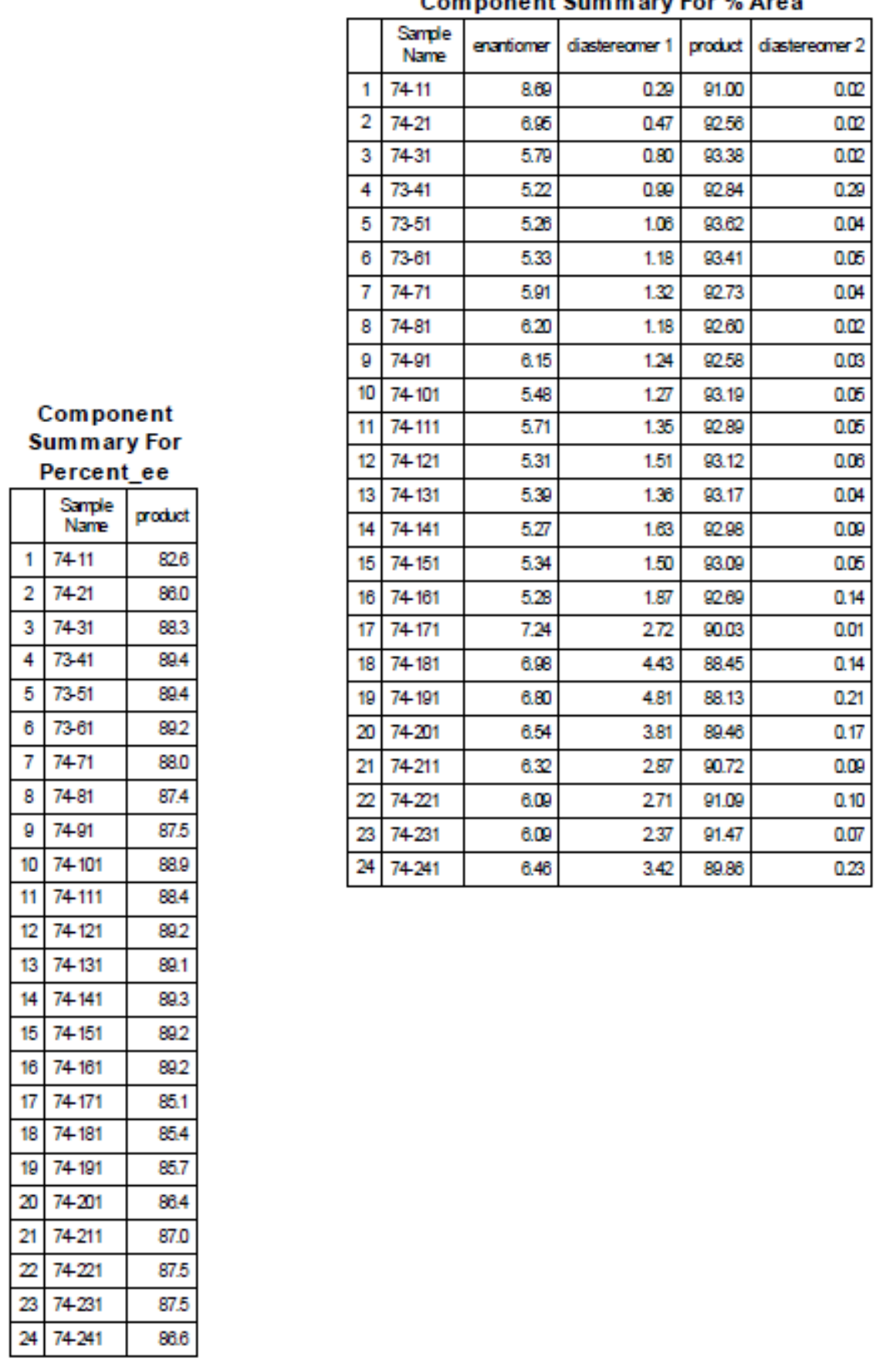


Figure S6. HPLC traces for filtrates (24 cycles, 97\% recycling ratio)

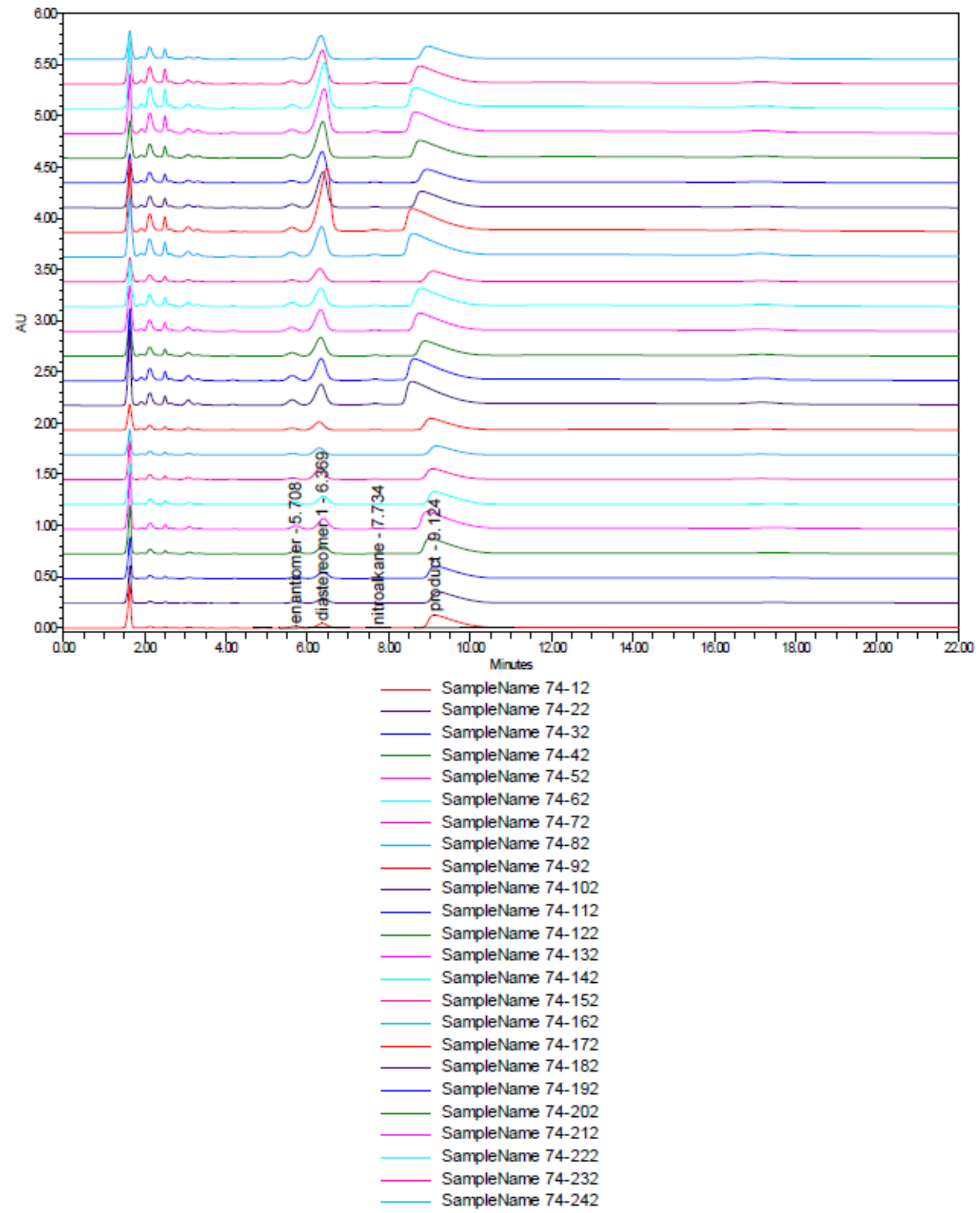


Component Summary For \% Area

Component Sum mary For Percent_ee

\begin{tabular}{|c|c|c|}
\hline & $\begin{array}{l}\text { Sample } \\
\text { Name }\end{array}$ & product \\
\hline 1 & 7412 & 910 \\
\hline 2 & 7422 & $\$ 03$ \\
\hline 3 & 7432 & 89.5 \\
\hline 4 & 7442 & 87.9 \\
\hline 5 & $74-52$ & 883 \\
\hline 6 & $74 \% 2$ & 882 \\
\hline 7 & 7472 & 888 \\
\hline 8 & 7482 & 87.2 \\
\hline 9 & 7482 & 87.8 \\
\hline 10 & 74102 & 888 \\
\hline 11 & 74112 & 858 \\
\hline 12 & 74122 & 848 \\
\hline 13 & 74132 & 88.5 \\
\hline 14 & 74142 & 88.5 \\
\hline 15 & 74152 & 886 \\
\hline 16 & $74-162$ & 87.7 \\
\hline 17 & 74172 & 888 \\
\hline 18 & 74182 & 884 \\
\hline 19 & 74192 & 882 \\
\hline 20 & 74202 & 88.8 \\
\hline 21 & 74212 & 804 \\
\hline 22 & 74222 & 888 \\
\hline 23 & 74232 & 88.5 \\
\hline 24 & 74242 & $\infty 00$ \\
\hline
\end{tabular}

\begin{tabular}{|c|c|c|c|c|c|c|}
\hline & $\begin{array}{l}\text { Sample } \\
\text { Name }\end{array}$ & enartioner & diastereomer 1 & nitroalkane & product & diastereaner 2 \\
\hline 1 & 7412 & 3.88 & 11.75 & 0.32 & 8390 & \\
\hline 2 & 7422 & 4.14 & 14.20 & 0.51 & 81.10 & \\
\hline 3 & 7432 & 4.38 & 18.05 & 0.68 & 78.86 & \\
\hline 4 & 7442 & 5.00 & 15.12 & 0.73 & 7902 & \\
\hline 5 & 7452 & 4.79 & 17.42 & 0.83 & 76.87 & \\
\hline 6 & 7462 & 4.67 & 19.88 & 0.82 & 74.27 & \\
\hline 7 & 7472 & 3.64 & 28.86 & 0.88 & 6210 & 4.34 \\
\hline 8 & 7482 & 4.57 & 22.94 & 0.87 & 6090 & 4.58 \\
\hline 9 & 7492 & 4.50 & 20.51 & 0.87 & 60.10 & 4.82 \\
\hline 10 & 74102 & 4.84 & 20.88 & 0.98 & 6820 & 4.94 \\
\hline 11 & 74112 & 4.94 & 23.61 & 1.03 & 6508 & 5.18 \\
\hline 12 & 74122 & 4.86 & 29.34 & 1.04 & 5025 & 5.36 \\
\hline 13 & 74132 & 4.45 & 27.79 & 1.07 & 61.25 & 5.29 \\
\hline 14 & 74142 & 4.60 & 24.68 & 1.15 & 63.79 & 5.61 \\
\hline 15 & 74152 & 4.13 & 31.32 & 1.13 & 57.79 & 5.45 \\
\hline 16 & 74162 & 3.98 & 28.68 & 1.19 & 60.41 & 5.61 \\
\hline 17 & 74172 & 267 & 48.70 & 0.81 & 45.13 & 246 \\
\hline 18 & 74182 & 3.62 & 42.89 & 0.81 & 49.53 & 2.83 \\
\hline 19 & 74192 & 298 & 45.88 & 0.91 & 46.68 & 3.28 \\
\hline 20 & 74202 & 3.58 & 41.23 & 0.83 & 5028 & 3.70 \\
\hline 21 & 74212 & 283 & 41.08 & 1.08 & 50.51 & 4.22 \\
\hline 22 & 74222 & 294 & 41.60 & 1.12 & 49.55 & 4.42 \\
\hline 23 & 74232 & 3.17 & 38.80 & 1.11 & 51.90 & 4.63 \\
\hline 24 & 74242 & 270 & 39.85 & 1.14 & 51.20 & 4.84 \\
\hline
\end{tabular}


Figure S7. Chiral HPLC trace for the isolated dried product (cycles 1-6, 24 cycles, 97\% recycling ratio)

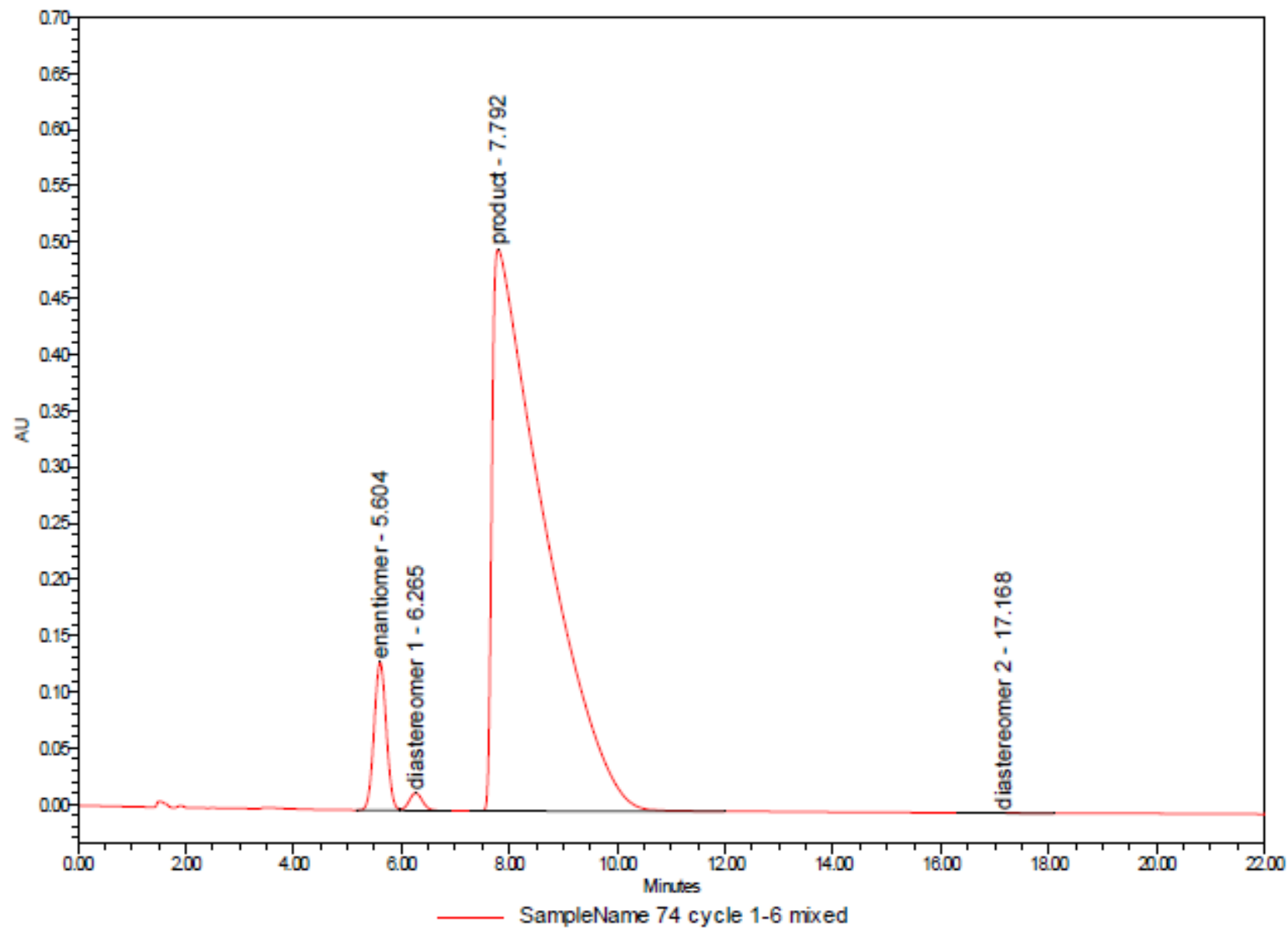

Component

Sum mary For

Percent_ee

\begin{tabular}{|c|c|r|}
\hline & $\begin{array}{c}\text { Sample } \\
\text { Name }\end{array}$ & product \\
\hline 1 & 74 cycle $1-6$ mixed & 88.3 \\
\hline
\end{tabular}

Component Sum m ary For \% Area

\begin{tabular}{|c|c|r|r|r|r|}
\hline & $\begin{array}{c}\text { Sanple } \\
\text { Name }\end{array}$ & enarioner & diatereomer 1 & product & dizstereomer 2 \\
\hline 1 & 74 cycle 1-6 mied & 5.79 & 0.75 & 83.45 & 0.01 \\
\hline
\end{tabular}


Figure S8. Chiral HPLC trace for the isolated dried product (cycles 7-16, 24 cycles, 97\% recycling ratio)

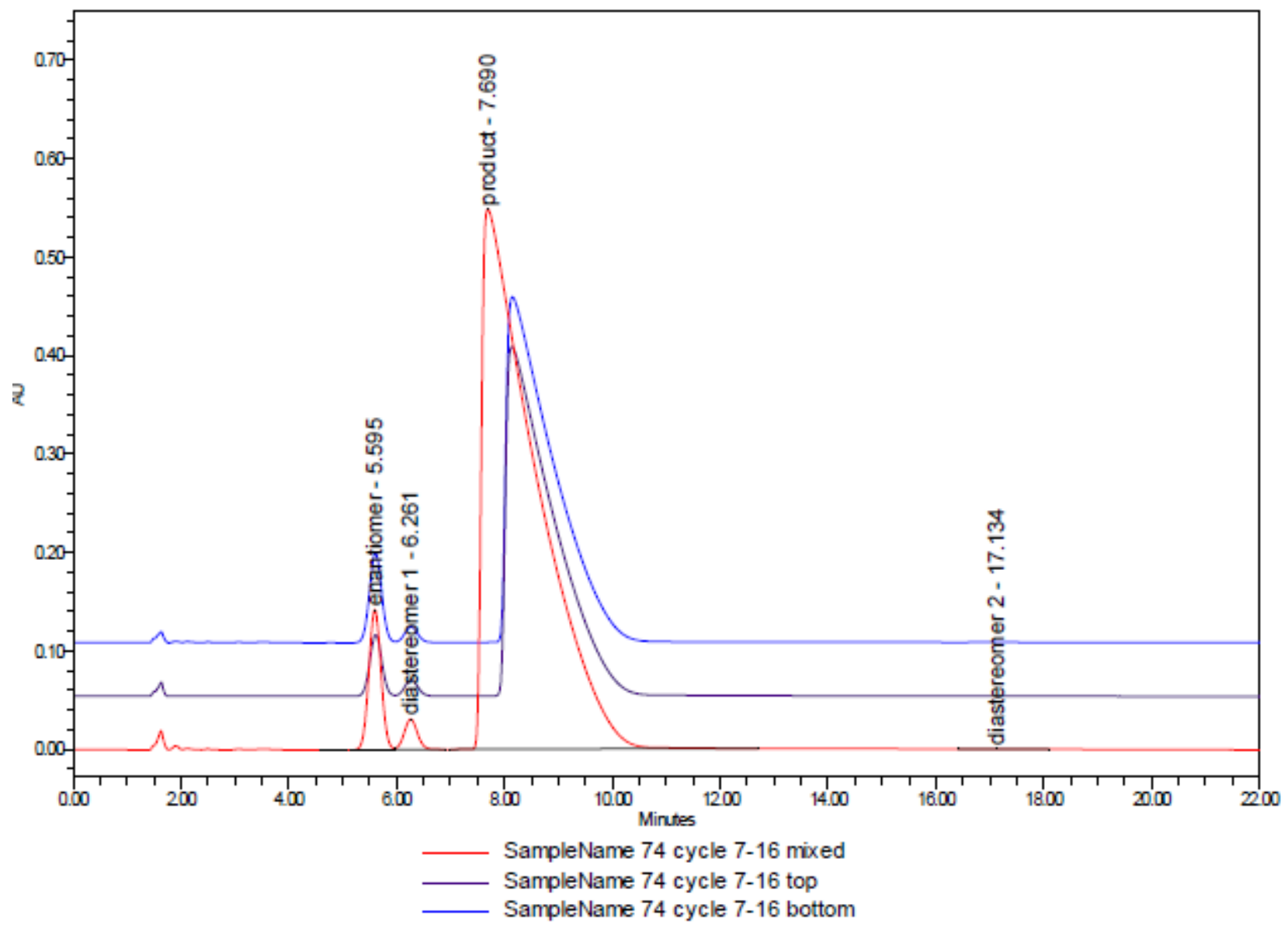

Component Sum mary For Percent_ee

\begin{tabular}{|l|l|r|}
\hline & \multicolumn{1}{|c|}{$\begin{array}{c}\text { Sample } \\
\text { Name }\end{array}$} & product \\
\hline 1 & 74 cycle $7-16$ mixed & 88.8 \\
\hline 2 & 74 cycle $7-16$ top & 91.2 \\
\hline 3 & 74 cycle $7-16$ bottom & 87.1 \\
\hline
\end{tabular}

Component Summary For \% Area

\begin{tabular}{|l|l|r|r|r|r|}
\hline & \multicolumn{1}{|c|}{$\begin{array}{c}\text { Sanple } \\
\text { Name }\end{array}$} & enartioner & dastereoner 1 & product & dastereoner 2 \\
\hline 1 & 74 cycle 7-16 mived & 5.53 & 1.30 & 93.13 & 0.02 \\
\hline 2 & 74 cycle 7-16 top & 4.30 & 1.27 & 94.36 & 0.02 \\
\hline 3 & 74 cycle 7-16 bottom & 6.39 & 1.23 & 92.34 & 0.03 \\
\hline
\end{tabular}


Figure S9. HPLC traces for the solid product (24 cycles, $97 \%$ recycling ratio)

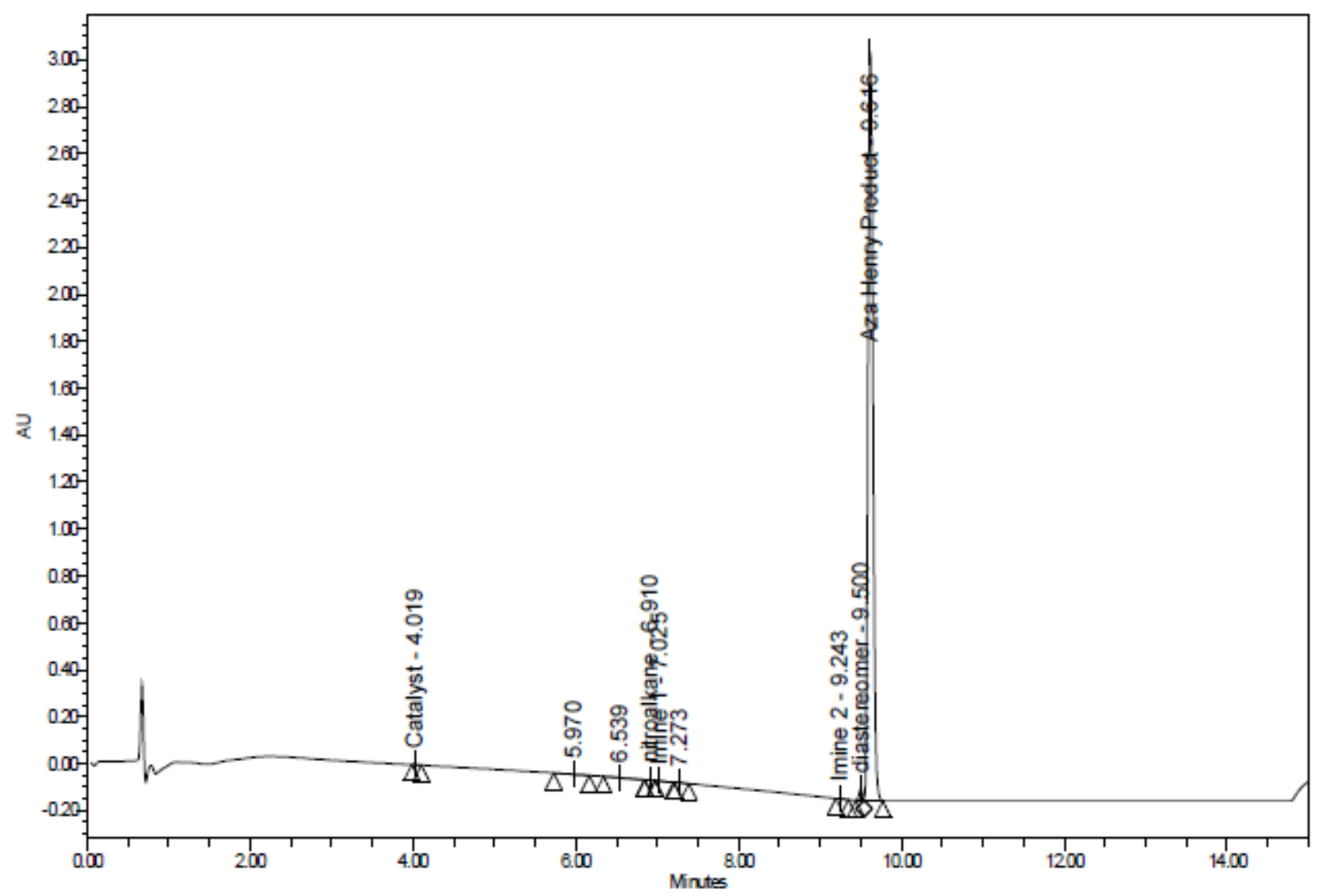

\begin{tabular}{|c|c|c|c|c|}
\hline & Name & $\begin{array}{c}\text { RT } \\
\text { (min) }\end{array}$ & $\begin{array}{c}\text { Area } \\
\left(\mu V^{\prime} \sec \right)\end{array}$ & $\%$ Area \\
\hline 1 & Catalyst 1 & 3.700 & & \\
\hline 2 & Catalyst & 4.018 & 5250 & 0.04 \\
\hline 3 & & 5.970 & $32 \pi 9$ & 0.02 \\
\hline 4 & & 6.539 & $49 \pi 7$ & 0.04 \\
\hline 5 & nitroalkne & 6.910 & 8254 & 0.08 \\
\hline 6 & Imine 1 & 7.025 & 4839 & 0.04 \\
\hline 7 & & 7273 & 13808 & 0.10 \\
\hline 8 & Imine 2 & 9.243 & 6473 & 0.05 \\
\hline 9 & diastereamer & 9.500 & 148303 & 1.08 \\
\hline 10 & Aza Herry Product & 9.616 & 13680845 & 98.59 \\
\hline
\end{tabular}




\section{Preliminary safety evaluation of oxime and nitro containing compounds}

Compounds containing nitro and oxime groups are often suspected to possess negative characteristics from a thermal hazards perspective, and they can potentially decompose with the release of high amounts of evolved heat and pressure. Compounds 2, 4, and 9 were evaluated by Differential Scanning Calorimetry (DSC) to determine their thermal decomposition behavior. Their propensity for shock sensitivity or ability to propagate an explosion can be evaluated by using Yoshida's correlation. ${ }^{2}$ While all three materials exhibit decomposition energies $>350 \mathrm{~J} / \mathrm{g}$, the combination of the onset of the exotherm with the magnitude of the heat release indicate that none of these compounds are expected to be shock sensitive or able to propagate an explosion. Of the three compounds, compound $\mathbf{2}$ would merit further testing in a physical test such as the Bam-Fallhammer test as its behavior in the Yoshida correlation was borderline. While these particular samples present as non-shock sensitive and non-explosion propagating, the thermal behavior of a compound is sensitive to its thermal history (i.e. mode of preparation, purity and state decomposition) and as such these samples should be re-examined whenever synthesized or aged in order to assess their thermal decomposition characteristics. 
Figure S10. DSC analysis for 1-chloro-4-(nitromethyl)benzene

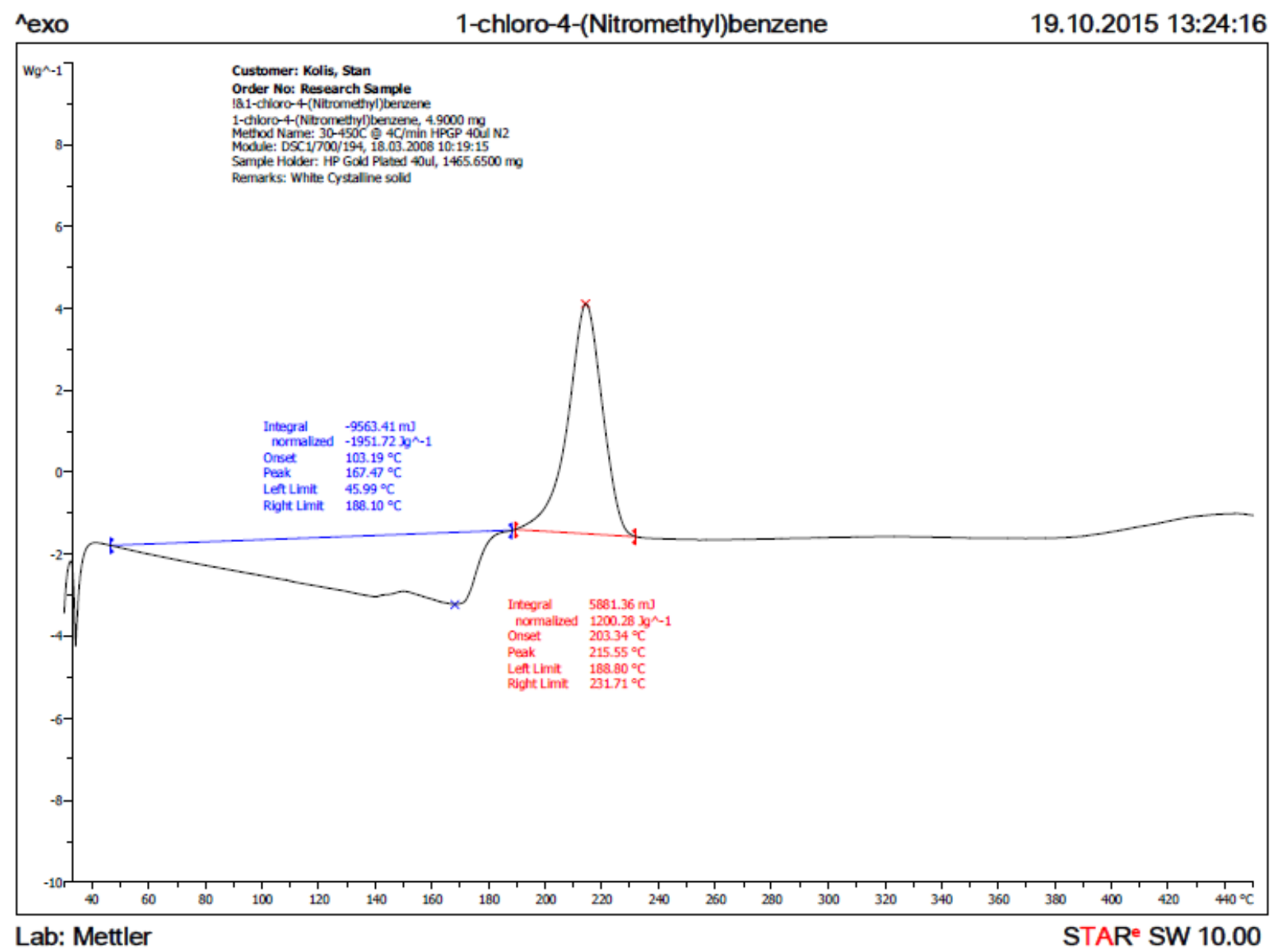


Figure S11. DSC analysis for tert-butyl-(1R,2S)-1,2-bis(4-chlorophenyl)-2-(nitroethyl)carbamate

^exo

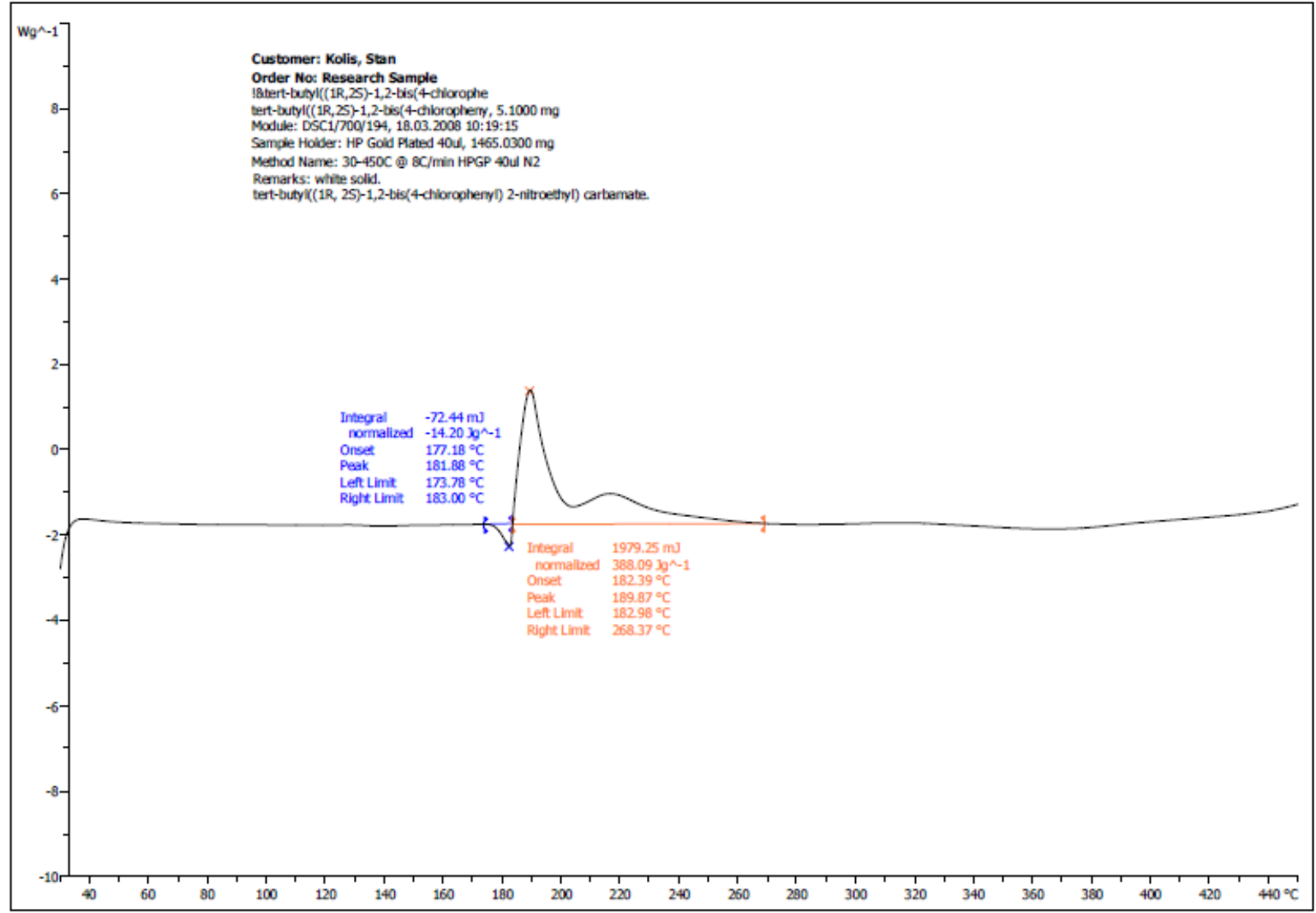

Lab: Mettler 
Figure S12. DSC analysis for 4-chlorobenzaldehyde oxime

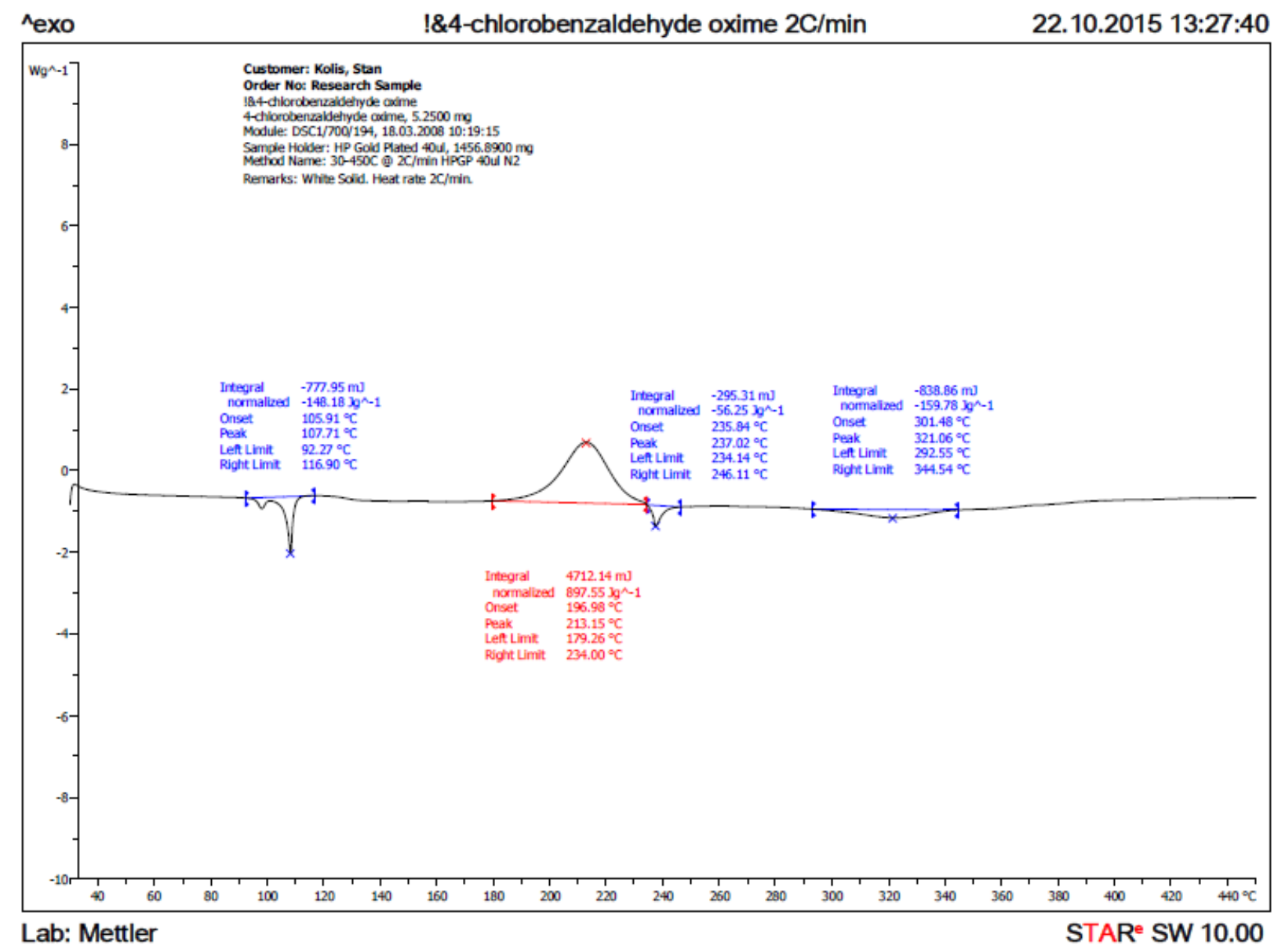




\section{References}

${ }^{1}$ (a) Levenspiel, O. Chemical Reaction Engineering. An Introduction to the Design of Chemical Reactors; John Wiley and Sons, Inc.: New York, NY, 1962. (b) Fogler, H. S. Elements of Chemical Reaction Engineering; Third ed.; Prentice Hall PTR: upper Saddle River, New Jersey, 1999.

${ }^{2}$ Yoshida, T.; Yoshizawa, F.; Itoh, M.; Matsunaga, T.; Watanabe, M.; Tamura, M. Prediction of Fire and Explosion Hazards of Reactive Chemicals (I). Estimation of Explosive Properties of Self-Reactive Chemicals from SC-DSC Data. Kogyo Kayaku 1987, 48, 311-316. 